\title{
Advancing passive sampling of contaminants in Environmental Science
}

\author{
Mayer, Philipp; Wania, Frank; Wong, Charles S.
}

Published in:

Journal of Environmental Monitoring

Link to article, DOI:

10.1039/c4em90004a

Publication date:

2014

Document Version

Publisher's PDF, also known as Version of record

Link back to DTU Orbit

Citation (APA):

Mayer, P., Wania, F., \& Wong, C. S. (2014). Advancing passive sampling of contaminants in Environmental Science. Journal of Environmental Monitoring, 16(3), 366-368. https://doi.org/10.1039/c4em90004a

\section{General rights}

Copyright and moral rights for the publications made accessible in the public portal are retained by the authors and/or other copyright owners and it is a condition of accessing publications that users recognise and abide by the legal requirements associated with these rights.

- Users may download and print one copy of any publication from the public portal for the purpose of private study or research.

- You may not further distribute the material or use it for any profit-making activity or commercial gain

- You may freely distribute the URL identifying the publication in the public portal

If you believe that this document breaches copyright please contact us providing details, and we will remove access to the work immediately and investigate your claim. 


\section{Environmental Science Processes \& Impacts}

Cite this: Environ. Sci.: Processes Impacts, 2014, 16, 366

\section{Advancing passive sampling of contaminants in environmental science}

\author{
Philipp Mayer, ${ }^{a}$ Frank Wania ${ }^{b}$ and Charles S. Wong ${ }^{c}$
}

DOI: $10.1039 / \mathrm{c} 4 \mathrm{em} 90004 a$

rsc.li/process-impacts

Passive sampling has seen a tremendous rise in popularity in recent years. Improved sampler designs and materials are being developed and tested. Samplers are deployed in a variety of environmental media and target different types of chemicals. Creative new ways of applying passive samplers and more sophisticated means of interpreting the results obtained by passive sampling are demonstrated. This themed issue showcases some of these latest developments in passive sampling research.

In these contributions, passive sampling approaches were applied to water, air, soil vapours, sediments and even fish tissue, whereas target analytes spanned a wide range in terms of chemical groups and physical chemical properties. Clearly, passive sampling has progressed well beyond measuring aqueous concentrations of legacy contaminants. Most of the presented methods were operated in the kinetic uptake regime and provided thus time weighted average concentrations, while other methods were operated in the

\footnotetext{
${ }^{a}$ Department of Environmental Engineering, Technical University of Denmark, Kongens Lyngby, Denmark. E-mail:philm@env.dtu.dk

${ }^{b}$ Department of Physical and Environmental Sciences, University of Toronto Scarborough, Toronto, Ontario, Canada.E-mail: frank.wania@utoronto.ca

${ }^{c}$ Richardson College for the Environment, University of Winnipeg, Winnipeg, Manitoba, Canada. E-mail: ch. wong@uwinnipeg.ca
}

equilibrium regime and provided new thermodynamic parameters such as chemical activities. The wide range of different passive sampling approaches, media and analytes clearly speaks to the huge promise of passive sampling in future research and monitoring.

Mills et al. (DOI: 10.1039/ C3EM00585B) present a synopsis of the state-of-the-art in passive sampling by summarising important topics from the $6^{\text {th }}$ International Passive Sampling Workshop and Symposium (IPSW) held in Bordeaux, France, in late June 2013. Most of the discussions at IPSW focused on passive sampling in water and sediments, especially the development of samplers for polar organic contaminants including POCIS, Chemcatcher and oDGT. The understanding of uptake kinetics and sorption of analytes to polar sequestration materials is still limited. Coupled with a lack of standardized calibration techniques and limited case studies in some aqueous media (e.g. drinking water), this means that further research is needed before polar passive samplers can be incorporated into largescale monitoring and regulatory programs. Research on passive water sampling of non-polar organic compounds continues, with a particular focus on a better understanding of the processes controlling uptake in silicone and low-density polyethylene (LDPE) samplers. For metals, DGT behavior is an area of active research, in particular on the effects of water chemistry during field deployments.

Some of the themes from the IPSW are investigated further in other contributions. Metcalfe et al. (DOI: 10.1039/ C3EM00508A) report on the occurrence and behaviour of selected pharmaceuticals and polar contaminants in drinking water via POCIS and grab sampling. POCIS was able to detect compounds not present in grab samples, while the latter was more useful for characterizing episodic events. Concentrations of some analytes that seemed to decrease over the time of deployment hint at the potential equilibration of these chemicals in POCIS. This was also observed in laboratory-based sorption-desorption studies, suggesting that further investigation on the limitations of POCIS uptake are warranted.

The DGT passive sampling technique is well-established for the analysis of metals in aqueous media. Uptake in the DGT is independent of water flow rate as long as the diffusive layer constitutes the main resistance to mass transfer. While this may be the case under most environmentally relevant conditions, Turner et al. (DOI: 10.1039/C3EM00574G) show, based on field deployments, that under low-flow conditions the aqueous-side diffusive boundary layer can pose a significant resistance to the uptake of uranium ions in DGTs. If boundary layer 
resistance is ignored, concentrations could be significantly underestimated compared to grab samples. Biofouling may also contribute to the overall mass transfer resistance. Turner et al. caution that such considerations should be taken into account when using DGT in longterm monitoring programs.

Passive sampling in complex and dense environmental matrices is a particularly exciting new development. Jahnke et al. (DOI: 10.1039/C3EM00589E) applied equilibrium sampling of polychlorinated biphenyls (PCBs) and hexachlorobenzene in eel tissue and sediments from a Swedish lake. Tissue and sediment were both brought into equilibrium with a reference polymer, and the concentration ratio between the equilibrated polymers yielded the chemical activity ratio between eel and sediment. This "chemometer" approach allows in situ bioaccumulation to be assessed on a thermodynamic basis. While concentrations of PCBs were higher in eels than in sediment, their activities were actually lower in the fish. This apparent contradiction is explained by higher partition coefficients for eel lipids compared to sediment organic carbon. The application of equilibrium sampling in two or more different environmental media can clearly provide new thermodynamically based insights into environmental fate and exposure processes.

Thomas et al. (DOI: 10.1039/ C3EM00695F) deployed polydimethylsiloxane (PDMS) coated glass fibers to assess the remediation of contaminated sediments by activated carbon amendments at three locations in the USA. Performance reference compounds were applied to correct for dis-equilibrium sampling, and estimated PDMS water partition coefficients were applied to calculate freely dissolved concentrations $\left(C_{\text {free }}\right)$ of PAHs and PCBs in the sediment. Vertical depth profiles in $C_{\text {free }}$ were related to sediment remediation activities, conventional grab sampling measurements and environmental quality criteria. Finally, the effect of activated carbon amendment on PCB bioaccumulation in benthic worms was related to the products of $C_{\text {free }}$ and the octanol-water partition coefficient.
McAlary et al. provided theory (DOI: 10.1039/C3EM00652B) as well as dedicated laboratory (DOI: 10.1039/ C3EM00128H) and field (DOI: 10.1039/ C3EM00653K) experiments in support of quantitative passive soil vapour sampling for volatile organic compounds. Passive sampling was operated in the kinetic regime, and known and reliable uptake rates were thus crucial for the calibration of the methods. These uptake rates had to be sufficiently low to avoid local depletion but still high enough to provide sufficiently low quantification limits. Uptake rates in the range of about 0.1 to $10 \mathrm{~mL} \min ^{-1}$ were found to be suited to deliver quantitative passive soil vapour concentration data with only a small bias, whereas an uptake rate of about $1 \mathrm{~mL}$ $\min ^{-1}$ was found to provide acceptable accuracy and sensitivity for most commonly-encountered water-filled porosities in unsaturated soils. Five different passive samplers were applied for the sampling of ten different volatile organic compounds of varying classes and physical properties. The results indicate that kinetic passive sampling can indeed provide soil vapour concentration measurements with good accuracy and precision.

Four contributions are field-based studies on the passive air sampling (PAS) of semi-volatile organic compounds (SVOCs). One of the most contentious issues in this field is the question whether particle-bound SVOCs can be sampled quantitatively. Bohlin et al. (DOI: 10.1039/C3EM00644A) tackled the question with an extensive outdoor calibration study for the commonly used PUF-disk based PAS that targeted several SVOC classes known to include substantial particle-bound fractions (PCDD/Fs, PBDEs). Sampling rates, accuracy and sensitivity for these substances were found to be low, suggesting that the potential of using PUF-based PAS for sampling particle-bound SVOCs quantitatively is limited. The study further demonstrated that sampling rates cannot be assumed to be the same for different target chemicals.

Another outdoor calibration study is presented by Khairy and Lohmann (DOI: 10.1039/C3EM00493G). Uptake of a variety of analytes in LDPE sheet-based samplers was recorded over a three-week period. Equilibrium partitioning coefficients between gas phase and LDPE were calculated from the field data and used to derive predictive linear free energy relationships with vapour pressure and octanol-air partition coefficients.

The exceptionally high uptake capacity of divinylbenzene-styrene copolymeric resin (XAD) for organic compounds allows for kinetic sampling of even relatively volatile substances. Gawor et al. (DOI: 10.1039/C3EM00499F) demonstrated kinetic regime sampling of several neutral perfluoroalkyl substances over time periods as long as a year even under tropical temperature conditions. Analysis of XAD-based PAS from the Global Atmospheric Passive Sampling (GAPS) network and several national campaigns for those neutral perfluoroalkyl substances provides not only a picture of their global distribution but also their first time trends in the atmosphere encompassing multiple years.

Wind-driven air sampler designs seek to overcome the low sampling rates of PASs that rely on diffusive uptake alone. Geoghegan et al. (DOI: 10.1039/ C3EM00498H) performed the first replicated study with a flow-through sampler for SVOCs and found reproducibility between triplicates to be $c a$. $20 \%$. When sampling pesticide vapour drift in close source proximity, eight hour sampling periods were sufficient to obtain easily quantifiable amounts of the target analyte. However, accuracy suffered during low wind conditions, when diffusion may have become the dominant route of uptake.

Liu and Wania (DOI: 10.1039/ C3EM00605K) explore how cluster analysis can be used to extract information from the results of PAS networks for SVOCs. Using multiple examples from around the world, they show that clustering allows for the separation of samples influenced by local sources from those that are representative of regional background conditions. One could envisage how a PAS network could be used in combination with cluster analysis to decide on the best location of a long term monitoring station for SVOCs.

The development of PAS for mercury is another area of active PAS research, which is reviewed in the contribution by 
Huang et al. (DOI: 10.1039/ capacity and kinetics, whereas carbon C3EM00501A). The recently signed Minnamata Convention increases the need for worldwide monitoring of atmospheric mercury, something that is most effectively accomplished with a reliable PAS. Plant based samplers are dismissed because of high variability in uptake based samplers appear to have the largest promise. Particular challenges are associated with the sampling of gaseous oxidized mercury and the measurement of dry deposition rates.

We believe that the field of passive sampling is still in its infancy and its true potential has yet to be realized. The apparent simplicity of passive sampling is at the core of this potential and betrays a wealth of opportunity. The contributions of this themed issue provide a glimpse of what is possible and we hope you enjoy reading them as much as we did. 